\title{
Odyssey in the evolution of a paleopathologist
}

\author{
Bruce M. Rothschild ${ }^{1,2}$ \\ ${ }^{1}$ West Virginia School of Medicine, Morgantown, WV 26506, USA \\ ${ }^{2}$ Carnegie Museum of Natural History, Pittsburgh, PA 55213, USA \\ Correspondence to: Bruce M. Rothschild (spondylair@gmail.com)
}

Received: 14 October 2016 - Revised: 17 November 2016 - Accepted: 19 November 2016 - Published: 19 December 2016

\begin{abstract}
A recent report suggesting perceived limitations of and opportunities in the study of paleopathology suggested the importance of incorporation of scientific methodologies. It seems reasonable to also explore how those methodologies are developed and, indeed, how one approaches paleopathology as a science. The development of one such paleopathologist is delineated from his serendipitous observations to application of hypothesis generation and subsequent testing approach developed during basic medical science education. This approach resulted in recognition of how much he thought he knew was actually contrary to the facts. A critical factor was the collaborative approach with specialists in other fields, wherein linguistic confusion was overcome and perspectives refined by point-counterpoint analysis of hypotheses. The limited reliability of tertiary information was clearly exposed through examination of primary sources - original articles rather than what might be referred to as "meta-analyses".

It became clear that linguistics was not the only challenge; application of techniques had to be observed and validated. Without validation one might obtain precision (method repeatedly reveals same results) but at the expense of accuracy (assurance that the method actually assesses the question). Paleontological studies are generally limited to examination of organisms and their traces. Archeologically based studies incorporate additional sources of information (e.g., historic), but are no less subject to such semantic and methodological issues. Proof of concept studies provided new windows to recognition not only of disease but to previous anatomical challenges (e.g., localization of direct muscle attachment sites and distribution). Trans-phylogenetic representation of disease falsified speculation that "evolution" would preclude analysis through time. Pathology is an intrinsic component of life and transcends both species and time. Knowledge gained in a given species and time can be applied to similar disease
\end{abstract}

manifestations in other species in modern time. Once speculations were tested and either verified or falsified, paleoepidemiologic approach allowed identification of patterns of spread and even application of that knowledge to recognition of human migration patterns. Proof of concept studies provided new windows to recognition not only of disease but to previous anatomical challenges (e.g., localization of direct muscle attachment sites and distribution).

\section{Introduction}

A perspective to some of the challenges facing the field of paleopathology was recently provided (Roberts, 2016), but the issue seems a bit more complex. Desiring to provide additional insights to that discussion, it seems appropriate to analyze the development/evolution not of paleopathology but rather of the individual who studies it, at least of the author of the current analysis. Solving a problem requires its recognition. That requires modification of search images to answer specific questions. This seems a critical component of a scientific approach to the origins of disease. This is also a critical component of educational approaches for health care. My participation in this field was predicated on the belief that paleopathology could transcend observational reporting and be approached in a scientific, hypothesis testing-driven manner. It was accompanied by the desire to augment the attitude (architectural visibility) specifically of arthritis within graduate and postgraduate education of both medicine and anthropology. Given minimum curriculum time, the challenge was to present information in a memorable way, something perhaps unexpected, but which resonates with early life experience.

Directing my approach was the claim that arthritis was common in dinosaurs; an interesting claim that I was unable to substantiate in North American museum collections 
(Rothschild, 1990). Their joints appeared normal. All I found were vertebral body (centra) spurs. Vertebral spurs (also called osteophytes) are adjacent to disks, not joints. They also are quite common in humans. They are so common, in fact, that they were once thought to cause back pain. Once it was realized that such spurs are also as common in the absence of back problems, they ceased to have any significance, let alone be reasonably called arthritis in humans. Our current understanding of the implication of vertebral spurs has been revised with the recognition that vertebra in dinosaurs are separated by a synovial-lined joint, not an intervertebral disk (Rothschild et al., 2016). So, the original attribution of vertebral spurs as osteoarthritis was correct. However, there is still no evidence that dinosaurs were adversely affected.

Attending a medical meeting in London, I, of course, visited the British Museum of Natural History (BMNH), now called the National History Museum (NHM). The "of course" perhaps requires explanation. I grew up with the American Museum of Natural History (AMNH), specifically its dinosaur halls and reading AMNH publications about Roy Chapman Andrews of Gobi Desert fame. It left me with the false impression that all dinosaurs were from his Gobi Desert site. I therefore was severely traumatized in childhood when the Gobi was closed to westerners. I perceived my career choice as a paleontologist to have been rendered inaccessible and turned to a career providing medical care. I never actually lost my early appreciation for fossils and was delighted to find the foyer of the BMNH occupied by several dinosaur skeletons. More than just occupied, they were placed on pedestals - which I thought quite appropriate. The resultant viewpoint permitted visualization and recognition of vertebral (specifically cervical) fusion in the horned dinosaur, Triceratops. This area was not visible or at least was unapparent in museum exhibits in other museums. The natural question was whether the BMNH skeleton represented a diseased individual or if the fusion was a species characteristic.

My education as to feasibility of recognizing disease in the paleontological and archeological record and the importance of serendipity in overcoming preconceived notions.

The search for an answer to that question eventually led to the University of Kansas Biodiversity Institute \& Natural History Museum, where I met Larry Martin. While he did not have the representative Triceratops bones of interest, he decided to avail himself of my potential medical knowledge. He showed me a set of coalesced fossil vertebrae that had previously eluded explanation. Observation of filigree (Aero candy-like bubbly) reaction led me to suggest that the problem was an infection (Rothschild and Martin, 1992, 2006). My response was that it appeared to be the result of an infection, but to prove that hypothesis the specimen would have to be sectioned. I turned to depart, when Larry invited me into his laboratory to actually cut the specimen. In addition to revealing the anticipated bony alterations, sectioning revealed a sequestrated abscess and an imbedded shark tooth (Rothschild and Martin, 1992). The latter was from the predator responsible for the infection and was the first actual proof of predation, as opposed to simple scavenging. Learning that destructive analysis (e.g., sectioning) would be considered, I gathered the courage to request sectioning of a normal vertebra for comparison. That vertebra proved to be anything but normal. An internal band of dead bone identified a pathology typically associated with decompression syndrome related to deep diving and rapid ascents (Resnick, 2002; Rothschild and Martin, 1987). This was fossil evidence in a 65-millionyear-old marine reptile, and it was not an isolated phenomena. It had occurred not only in every individual of that same species but was universally present in half a dozen others and was independent of location, from Kansas to South Dakota to Alabama to Belgium (Martin and Rothschild, 1989; Rothschild and Martin, 1987, 2005).

The next problem was explaining the occurrence of avascular necrosis in a marine lizard. Although there are a score of potential causes in humans, most were not reasonable considerations in a mosasaur (Rothschild, 1982; Resnick, 2002) (e.g., we felt that sickle cell anemia was unlikely). Although the mosasaur swam in a primordial soup, the alcohol level was not high enough to cause avascular necrosis (as it does in some alcoholics today). We identified only three reasonable considerations: radiation, bismuth poisoning and decompression syndrome (the bends). The latter was initially included only for completeness. Physical measurements revealed no evidence of radiation and x-ray diffraction revealed no evidence of excess bismuth.

We were left with the conclusion drawn by one of Arthur Conan Doyle's characters. When you have eliminated the impossible, the remaining conclusion (however improbable) must be the answer (Stein, 2009, p. 229). However, we had difficulty reconciling decompression syndrome with absence of an external air source. Larry and I pondered this for a year. We then discovered the literature on Japanese Pearl Divers (Rahn and Yokoyama, 1965). One group of divers (who did not use an external air supply - e.g., scuba) did get the bends. Repetitive diving with short inter-dive intervals was responsible. Applying this new knowledge to our mosasaurs allowed us to determine that two genera were repetitive divers. We subsequently confirmed that genera susceptibility was uniform, independent of location. Mosasaurus from Belgium and Alabama were always affected. Clidastes, whether from Kansas or Alabama, were never affected (Rothschild and Martin, 1987).

My interest was/is in pre-mortem skeletal alterations and how prevalence changed over time and what characteristics changed over time in the diseases themselves. I therefore concentrated on my original question - Triceratops cervical fusion: disease or phylogeny? I soon realized the necessity of distinguishing apparent fusion (e.g., incomplete specimen preparation) and, actually, intervertebral fusion, which often required x-ray examination (Resnick, 2002; Rothschild and Martin, 2006). One important subject of that phylogenetic survey included one of the dinosaurs that originally drew me 
to paleontology, Roy Chapman Andrews' Protoceratops. I knew of the mounted specimen at the Carnegie Museum of Natural History and communicated an inquiry as to the possibility of x-raying the specimen. I did not hear back from the Carnegie Museum, but instead started receiving calls from representatives of the national media. They asked to interview me, as the Carnegie Museum had taken their Protoceratops to a veterinary radiology laboratory and were having it x-rayed for me. It must have been a slow news day, as the story received $7 \mathrm{~min}$ of national television coverage and led to my long-time appointment as a Carnegie Museum Research Associate.

\section{Overcoming semantic variation and speculation versus evidence-based diagnosis}

The initial interaction with Larry Martin also led to a long collaboration. Its productivity was due in no small part to our many arguments, which were very much debates - in which the judges were actually ourselves. We each had to convince the other of our perspectives or have them disabused. It became obvious that we shared a common language, often total disparate in meaning (Rothschild and Martin, 2006; Rothschild et al., 2013). Much of our discussions related to clarification of the specific (medical versus paleontological/anthropological) meaning of particular terms. We also had preconceived concepts of the training involved in our respective fields. He initially assumed that a data-based set of criteria had been established for recognition of disease in defleshed bones, but recognized that deficiencies of such a population-based database had not been previously defined, a problem that curtailed efforts for scientific paleopathology.

Opinions were offered as to how a given disease might affect the skeleton, but most of those speculations had never been tested/validated (Brothwell and Sandison, 1967; Ortner and Putschar, 1981; Rothschild, 1996; Steinbock, 1976) - and that has been my lifelong effort (more on this later). I have referred to my approach as "evidence-based", adopting the term from its medical application which describes ideas or approaches that have actually been tested. Clinical trials of a therapeutic (e.g., medicinal) intervention are one such example.

My perspective of the curriculum involved in paleontological education also proved inaccurate. My initial submission of manuscripts to paleontological journals were almost universally criticized for containing too much "medicalese". I was perplexed, as I did not recognize any of the utilized terms as medical in derivation. My conundrum was resolved when Nick Hutton III of the Smithsonian asked me to perform a computerized tomographic scan of the Permian amphibian Eryops for his study of ear anatomy. I was happy to help. I asked him for a special favor - that he underline every term representing medicalese in one of my manuscripts. The result was eye-opening. All the medicalese terms were what I per- ceived as physiology. As physiology appears a component of freshman biology courses, I had been unaware that physiology was not part of anthropological and paleontological curricula. Those insights facilitated subsequent interdisciplinary interactions.

\section{Recognition of the interdisciplinary challenges of interpreting the historical record}

One approach to the understanding of population health and the disorders which affect it is to examine the historical record. Perhaps the most reliable information derives from unfiltered, written intra-professional communications (letters). Subsequent summaries (perhaps referable as metaanalysis) must be viewed circumspectly (Rothschild et al., 2013). Synchronic writings likely share a common vocabulary and possibly the implications of the terminology involved. However, if the meta-analysis is performed by an individual in a different field than the original observer, that shared vocabulary could still have very different meanings. It should be recalled that often interpretations, rather than observations, are recorded; those observations being interpreted according to the medical and sociological concepts of the time when they are recorded. Whether written word, painting or sculpture, those art forms provide a window to ancient perspectives of health and disease, if not actually necessarily reflecting the character of a given disease at the time (Mitchell, 2011).

Access to historical information is complicated by variable accessibility of original documents, knowledge of word meanings at the time, conventions and imagery of those times and of course ability to accurately translate those documents (West et al., 2016). The artistic convention of flexed metacarpal phalangeal joints, for example, gives the false impression of disease-related ulnar deviation, suggesting presence of inflammatory arthritis, when it is simply the artistically adapted pose. Texts, medical or otherwise, reflect the perspective of the civilization in which they are compared (Mitchell, 2011).

As descriptions are often copied from text to text by individuals who have never even seen the disease/phenomenon, it is essential to examine primary sources. Such is exemplified by 16 th and 17 th century English writings blaming "lead air" for plaque - related to fleeing rats. That commentary mirrors the description of Avicenna 500 years earlier. It was not actually a contemporary observation but essentially "plagiarism" of earlier work (Mitchell, 2011). Errors occurring in texts are imported from older documents. Handwriting problems with unintelligible or damaged portions of text and poetic license in translation and idiom are problematic. "La maladie de l'ost" was mistranslated as camp fever (an infectious process) when actual intent was scurvy. And of course, one wonders as to what was meant in the Rochester poorhouse 
death record identifying an individual who died from "embarrassment".

A corollary is that description in a text does not necessarily document presence of the disease/phenomenon in the population wherein the author functions (Alvarez-Millan, 2000; Savage-Smith, 2000). The challenge of illustration lies in what the artist wished to emphasize and their personal preferences or agenda (Cunningham, 2000, p. 13; McVaugh, 2006). Even modern reports suffer from bias in choice of articles included or excluded related to pet theories and inconvenient evidence (Bouwman and Brown, 2005; Grauer, 2012; Harper et al., 2014; Heathcote et al., 1998; Powell and Collins, 2005; Roberts et al., 2012; Rothschild and Rothschild, 1998a).

\section{A turning point and establishment of critical databases (Table 1)}

My sojourn in Kansas City came to an end with the advent of a dramatic change in Medicare. I had been director of education for two university programs that involved four residencies. When Medicare introduced a reimbursement system based on a protocol derived by a Yale University researcher for research, not patient care activities, a large teaching hospital was reduced below the critical mass required for postgraduate medical education and it was time to move on.

Rheumatologists have always been in short supply and I was recruited to organize a teaching program in Youngstown, Ohio. A physical anthropologist learned of my effort and inquired as to possible participation. That led to an extraordinary collaboration in patient care and research. My interest in characterizing disease effects on bone as population phenomenon had long been stymied because of my lack of familiarity with resources. That was remedied by Robert Woods, who knew whose closets contained the requisite skeletons. Once we characterized bony alterations in the major disorders commonly present as population phenomena (Rothschild and Martin, 2006; Rothschild and Rothschild, 1995, 1998b; Rothschild and Woods, 1991a; Rothschild et al., 1990, 1992a, b, 2002), we confirmed the findings by comparison with bony alterations of contemporary afflicted individuals - using X-rays as the common denominator (Resnick, 2002; Rothschild and Martin, 2006). We then had the requisite profiles necessary for the recognition of these diseases in the archeological record.

Given the skeletal impact of a given disease in populations represents a spectrum (Resnick, 2002; Rothschild and Martin, 2006), I predicted that extrapolating perspectives from archeological sites would prove only limited reliability if based on the findings in a single afflicted individual. Thus an epidemiologic approach seemed appropriate.

\section{Paleo-epidemiology: from the one to the many (Table 1)}

Illustration of pathological alterations of bone have traditionally been predicated upon classic examples, those that reflect severe or at lease dramatic cases (Aufderheide and Rodriguez-Martin, 1998). Those are far from typical and present a perspective/search image, utilization of which would overlook many individuals afflicted with the disease. The classic example is a very valuable tool for teaching disease concepts in a memorable fashion. However, it must be recalled that classic examples are typically the result of a search that may have taken more than 20 years. It is also atypical of its general population appearance.

With apologies to Spock, paleo-epidemiology transcends the classic example, from the one to the many. An additional challenge of classic examples is that they are not necessarily pathognomonic. They do not necessarily have an appearance that is unique to (can be caused by) only one disease or process. Actually, there is often great overlap.

Pathology-related bone alterations form a spectrum not only from mild to severe but also in extent and skeletal distribution (Resnick, 2002; Rothschild and Martin, 2006). This is well documented by individuals afflicted with spondyloarthropathy, a form of inflammatory arthritis which is usually pauciarticular (affecting less than five joints) in distribution (Resnick, 2002; Rothschild and Woods, 1991a). Usually is not always, and $5 \%$ of afflicted individuals actually have involvement of almost every peripheral joint in the body. A five-percenter could, for purposes of discussion, be considered an outlier. Such an individual would be difficult to distinguish from one afflicted with rheumatoid arthritis. However, examination of afflicted populations would identify the outlier nature of the individual sufficiently to avoid misdiagnosis. Those spectra of bony alterations are so reproducible that the manifestations of any 20 individuals from afflicted populations are indistinguishable epidemiologically (Rothschild and Rothschild, 1993).

The power of paleo-epidemiology has proven extraordinary, allowing tracing of various varieties of osseous pathology back to the Permian, 300 million years before present and to identify disease origins (Rothschild and Martin, 2006). Clearly comparable across contemporary populations, paleoepidemiology has in the past suffered from its own mythology - the speculation that comparison is not feasible and that diseases change too much to compare ancient and modern pathologic observations (Wolff, 2008). If that were true, paleopathology would be relegated to a series of case reports, a curiosity cabinet and perhaps simply an old-fashioned carnival sideshow, lacking relevance and only generating what might be called "prurient" interest. Fortunately, that speculation proved false (Rothschild and Martin, 2006; Rothschild et al., 2013).

Not only are manifestations in samples afflicted with a given disease unchanged over millennia, the search for inter- 
Table 1. Sample of insights/outcomes from application of evidence-based approaches.

\begin{tabular}{|c|c|c|}
\hline Scientific approach & Disease/phenomenon studied & Insights/outcomes \\
\hline \multirow{26}{*}{$\begin{array}{l}\text { Establish disease characteristics } \\
\text { as a population phenomenon }\end{array}$} & \multirow[t]{2}{*}{ Rheumatoid arthritis } & New World origin \\
\hline & & Age at least 6500 years \\
\hline & \multirow[t]{9}{*}{ Spondyloarthropathy } & Identified in Permian \\
\hline & & Recognized in dinosaurs \\
\hline & & Trans-mammalian and unchanged \\
\hline & & in character through time \\
\hline & & Geometric increase in prevalence \\
\hline & & over time in horse and rhinoceros clades \\
\hline & & $\begin{array}{l}\text { Recognized in contemporary reptiles, } \\
\text { especially varanids }\end{array}$ \\
\hline & & $\begin{array}{l}\text { New approach to treatment of contemporary } \\
\text { animals, including humans }\end{array}$ \\
\hline & & Correlation with tuberculosis \\
\hline & \multirow[t]{2}{*}{ Crystal-related arthritis } & Gout in tyrannosaurs \\
\hline & & $\begin{array}{l}\text { Calcium pyrophosphate deposition disease } \\
\text { (CPPD) in varanids }\end{array}$ \\
\hline & \multirow[t]{2}{*}{ Tuberculosis } & Extended history into the Pleistocene \\
\hline & & $\begin{array}{l}\text { Endemic in Pleistocene bison, musk ox, } \\
\text { big horn sheep and mastodon }\end{array}$ \\
\hline & \multirow[t]{2}{*}{ Both DNA and lipid analysis } & Mycobacterium bovis is derived from \\
\hline & & M. tuberculosis (converse of prior thinking) \\
\hline & \multirow[t]{3}{*}{ Treponemal disease } & $\begin{array}{l}\text { Proof that syphilis, yaws and bejel are } \\
\text { caused by different organisms and unchanged } \\
\text { through time }\end{array}$ \\
\hline & & New World origin of syphilis \\
\hline & & $\begin{array}{l}\text { Clarification of the role of Columbus in } \\
\text { spread of syphilis }\end{array}$ \\
\hline & Avascular necrosis/decompression & $\begin{array}{l}\text { Diving habits of marine reptiles and time } \\
\text { course of development }\end{array}$ \\
\hline & Neoplasia/tumors & Dinosaur and therapsid affliction \\
\hline & Osteoarthritis & Product of atypical environments \\
\hline & Stress fractures & Common in ceratopsians \\
\hline & \multirow[t]{2}{*}{ Developmental anomalies } & Osteochondrosis in hadrosaurs \\
\hline & & Hemivertebra and spina bifida in the Permian \\
\hline Thermography (heat dissipation) & Periosteal reaction and taphonomy & $\begin{array}{l}\text { Clearly distinguishes and confirms accuracy } \\
\text { of macroscopic assessment }\end{array}$ \\
\hline \multirow[t]{3}{*}{$\begin{array}{l}\text { Surface microscopy using epi-illumination } \\
\text { technique }\end{array}$} & Bone surface defects & $\begin{array}{l}\text { Criteria for distinguishing vascular and } \\
\text { neurologic apertures and structures }\end{array}$ \\
\hline & \multirow[t]{2}{*}{ Muscle attachments } & Clearly identifies tendinous attachments \\
\hline & & $\begin{array}{l}\text { For the first time identifies fleshy muscle } \\
\text { attachments }\end{array}$ \\
\hline
\end{tabular}

mediates (between different diseases) has so far proven unsuccessful. Classic of such negative evidence is analysis of treponemal disease. Three osseous varieties were identified, with no intermediate pattern, even those when replacement of one by another was documented. Bejel in Mexico was replaced by yaws with the Aztec invasion and by the syphilis that the Spanish subsequently introduced. No populations with intermediate manifestations have been discovered and the prevalence, age and skeletal distribution of those three treponematoses are so different that any intermediate form would be prominent, if such had occurred. The differences are so substantial that even preconceived notions of what was expected in a 2000-year-before-present Nubian sample did not interfere with recognition that they had an unanticipated character (Rothschild and Rothschild, 1996a). Examination of prevalence, age and skeletal distribution clearly documented the presence of bejel, which at that time was its earliest recognized occurrence. 


\subsection{Rheumatoid arthritis}

The first survey was for rheumatoid arthritis. Was it a new disease? We documented that rheumatoid arthritis was present in North America as long as 6500 years before present (Rothschild, 1994a; Rothschild et al., 1990) while there was no scientific evidence for its existence in the Old World as recently as 500 years before present (Kwiecinski and Rothschild, 2016; Rothschild, 1994a, 2013; Rothschild et al., 2004). It was quite limited geographically - to a $90 \mathrm{~km}$ wide swath surrounding the Green and western portion of the Tennessee rivers - for over 5000 years, and spread to Ohio 1000 years ago. It was only 300 years ago that it could be identified outside that catchment area (Rothschild, 2001; Rothschild and Woods, 1990; Rothschild et al., 1992b).

\subsection{Trans-phylogenetic reproducibility of disease (Table 1)}

The Hamann-Todd collection had a sentinel impact on my subsequent work. The privilege of working in this superbly curated collection also highlighted the importance of search images. Interested in forms of arthritis which produce holes (erosions) that I bone, I noticed an odd-looking articulated forearm. I was informed that the Todd collection also included nonhuman primates and that the forearm belonged to one of them: a gorilla. It seemed reasonable to then examine gorilla skeletons, and they indeed had an erosive arthritis (Rothschild and Woods, 1989). That arthritis was characteristic of a form identical to that seen in humans who did not have rheumatoid arthritis, but who had another form of arthritis, spondyloarthropathy. As I documented the gorilla arthritis as a population phenomenon, I realized that I had not seen the skeleton of the propositus, the forearm of which had stimulated the study. I then learned that it was not actually a gorilla but was from a chimpanzee. So, then we studied chimpanzees and the phylogenetic distribution of examined species expanded from there (Nunn et al., 2007; Rothschild and Rothschild 1994, 1996b, 2000; Rothschild and Rühli, 2005a, b; Rothschild and Woods, 1989, 1991b, 1992a, b, 1993, 1996; Rothschild et al., 1993, 1994, 1998a, b, 2001a, b, 2012). The erosive arthritis spondyloarthropathy is present in elephants, lions, tigers and bears (Rothschild et al., 1993, 1997, 1998a, b) - oh my! Every day brings new observations and new challenges. Publication on gorilla arthritis led to interaction with zoo veterinarians and the opportunity to examine and contribute to the care of captive gorillas (Neiffer et al., 2000).

\section{Discussion}

\subsection{Impediments to identifying and distinguishing among the varieties of disease}

I had been interested in studying skeletal impact and geographic distributions of the various treponematosis (one of which is responsible for syphilis), but literature on distinguishing among them was all speculative with no actual documentation of the character of all three, nor identification of what are the pertinent distinguishing features/characters (Brothwell and Sandison, 1967; Ortner and Putschar, 1981; Steinbock, 1976). I hypothesized that this question could only be answered by establishing the character of disease in individuals in whom the diagnosis had been clearly established by independent means. I knew where syphilis and bejel-afflicted populations were curated, but did not have access to populations with documented yaws. I was subsequently invited to lecture on arthritis in Guam, where historical records verified the presence of yaws where Cook visited (Howells, 1973; Stewart and Spoehr, 1952). Examination of several sites allowed characterization of skeletal involvement. It seemed that such an approach should evaluate population effects, but not be limited to manifestations previously suggested as diagnostic (Brothwell and Sandison, 1967; Ortner, 1981 Ortner and Putschar, 1981; Steinbock, 1976).

The approach I took was to consider each afflicted group as a separate species and characterize any and all findings that differed from each other and subsequently from what were considered to be normal, otherwise healthy individuals (Rothschild and Martin, 1992, 2006). The importance of the latter was emphasized by tibial flattening in archeological sites on Guam. That flattening differed from what was noted in populations with other treponemal diseases. However, my coauthor, who lived on Guam, failed to relate that tibial flattening was characteristic of the host population (Rothschild and Rothschild, 1998b). Once that oversight was recognized, that manifestation was of course deleted as a diagnostic criteria for disease. Such is the strength of the scientific method and emphasizes that even collaboration with individuals intimately familiar with a collection does not guarantee accuracy outside of each author's expertise (Rothschild and Martin, 2006). This was accomplished by identification of all abnormalities (as contrasted with other areas of the world), then refining them by eliminating characteristics specific to the Guam phenotype (Rothschild and Rothschild, 1998a).

\subsection{Serendipitous experience and concept of disease}

My perspectives were augmented by the opportunity to examine the skeletons of Sumatran tigers that had died allegedly from exposure to an insecticide that their vitamin Aintoxicated liver could not detoxify. Those skeletons provided a clear picture of vitamin A intoxication, identifying 
it as an entheseal rather than periosteal phenomenon (Rothschild et al., 1995). Review of Homo erectus National $\mathrm{Mu}-$ seum of Kenya (KMN) 1808 periosteal reaction was thus recognized as not related to hypervitaminosis A from allegedly eating carnivore liver (Walker et al., 1982), but rather represented an individual afflicted with one of the forms of treponematosis: yaws (Rothschild and Rothschild, 1995).

\subsection{The power of paleo-epidemiology (Table 1)}

The power of paleo-epidemiology allowed recognition of rheumatoid arthritis' North American origin and rebuttal of isolated reports alleging its Old World origin prior to 1492 (Kwiecinski and Rothschild, 2016; Rothschild, 1994a, b, 2013; Rothschild et al., 2004). Paleo-epidemiologic examination of the samples from which those claims derived allows confidential alternative diagnoses of spondyloarthropathy and even osteoarthritis, but it allows clear refutation of the rheumatoid arthritis diagnosis in pre-Columbian Europe.

The field of paleopathology is one of evolution of a learning curve, generating new concepts that are being tested in fossil and archeological sites. The challenge is to formulate an approach and to establish a testable hypothesis, which can be pursued, preferably without sacrificing the specimen. Thus, this nonrenewable resource (the specimens) will continue to be available for future examination and application of diagnostic techniques that are not even now a twinkle in the (mind's) eye of their developer.

\subsection{Proof of concept (Table 1)}

My career has been built on the foundation of crosspollination, that is utilization/application of training and knowledge obtained from other fields and approaches to new fields and new questions. This included the following:

1. application of residua of medical training to accurate diagnosis of skeletal pathology, recent, historical and ancient;

2. macroscopic examination of defleshed bones to explain radiologically recognized alterations;

3. macroscopic examination of skeletal samples/populations with evidence-based diagnoses to identify criteria for recognition of pathology in contemporary patients and in the skeletal record, as a fourth window to disease, supplementing the previously standard clinical, laboratory/histological and radiologic perspectives;

4. evidence-based macroscopic examination of skeletal samples/populations to identify the origin and spread of pathology;

5. evidence-based macroscopic examination of skeletal samples/populations to identify the phylogeneticspecificity of abnormal findings;
6. application of techniques new to the field;

a. thermographically distinguishing periosteal reaction from the pristine state and from taphonomic modification of bone;

b. surface microscopic recognition of anatomical and pathological features in bone;

c. surface microscopic explanation of hitherto unexplained bone alterations, as a fifth window to disease;

d. surface microscopic identification of fleshy, as well as tendinous muscle attachments.

\section{So, what is expertise?}

One of the pioneers of modern medicine, Sir William Osler, noted that "To study medicine without reading textbooks is like going to sea without charts, but to study medicine without dealing with patients is not going to sea at all". Semantics presents challenges that invade the world of communication, sometimes in nefarious ways. Understanding definitions is critical and can be misleading. "Experience" is one such example. The following scenario emphasizes the importance of establishing details and perhaps recognizing exaggeration. One medical report of a series described only two cases: one of experience, a single case; and "limited experience" was the term applied to having read about a problem/diagnosis, but not having actually seen a case (Spodick, 1975). Nothing substitutes for experience, but experience in the absence of reading simply leads to repetition, a.k.a. habits. Habits perhaps create precision, but the combination of experience and evidence provide the otherwise elusive accuracy. Thus, the erroneous report of treponemal disease in the Bahamian blue hole (Mack and Armelagos, 1992) could have been avoided by assuring that the individual(s) examining the skeletons possessed the skills to distinguish taphonomy and in vivo processes (Rothschild, 2000). The medical approach of observing student activity seems an excellent model for research in general.

Perspectives require independent validation. Perspective without validation is speculation. Advancement in understanding of our environment and history proceeds when such hypotheses are subjected to scientific evaluation. Promulgating untested speculations, in the absence of such testing or at the expense of contrary evidence, is mythology.

\section{Data availability}

All data sets referenced in this article are accessible from the sited references. 
Acknowledgements. Larry Martin and Harold Jeghers have been the most important components of my odyssey, the result of many hours of back and forth discussions that resulted in clarification of semantics and refinement of new concepts.

Edited by: F. Witzmann

Reviewed by: K. Pritzker and one anonymous referee

\section{References}

Alvarez-Millan, C.: Practice versus theory: Tenth-century case histories from the Islamic Middle East, Soc. Hist. Med., 2000, 293306, 2000.

Aufderheide, A. C. and Rodriguez-Martin, C.: Human Paleopathology, Cambridge University Press, Cambridge, 1998.

Bouwman, A. and Brown, T. A.: The limits of biomolecular paleopathology: Ancient DNA cannot be used to study venereal syphilis, J. Archaeol. Sci., 32, 703-713, 2005.

Brothwell, D. and Sandison, A. T.: Diseases in Antiquity: A Survey of the Diseases, Injuries and Surgery of Early Populations, Charles C. Thomas, Springfield, IL, 1967.

Cunningham, A. B.: Applied Ethnobotany: People, Wild Plant Use and Conservation, Earthscan, London, 2000.

Grauer, A. L.: A Companion to Paleopathology, Wiley Blackwell, Oxford, 2012.

Harper, K. N., Zuckerman, M. K., and Armelagos, G. J.: Syphilis: Then and now, Scientist, 2, 44-50, 2014.

Heathcote, G., Stodder, A., Buckley, H., Hanson, D., Douglas, M., Underwood, J., et al.: On treponemal disease in thWestern Pacific: Corrections and Critique, Curr. Anthropol., 39, 359-368, 1998.

Howells, W. W.: The Pacific Islanders, Charles Scribner Press, New York, 1973.

Kwiecinski, J. and Rothschild, B. M.: No rheumatoid arthritis in ancient Egypt: A reappraisal, Rheumatol. Int., 36, 891-895, 2016.

Mack, M. E. and Armelagos, G.: Skeletal analyusis of the Sanctuary Blue Hole Remains: The Lucayan Taino, Report submitted to the Bahamian Department of Archives, Nassau, The Bahamas, 1992.

Martin, L. D. and Rothschild, B. M.: Paleopathology and diving mosasaurs, Am. Sci., 77, 460-467, 1989.

McVaugh, M.: Niccolo da Reggio's translations of Galen and their reception in France, Early Sci. Med., 11, 275-301, 2006.

Mitchell, P. D.: Retrospective diagnosis and the use of historical texts for investigating disease in the past, Int. J. Paleopath., 1, 81-8, 2011.

Neiffer, D. L., Rothschild, B. M., Marks, S. K., Urvater, J. A., and Watkins, D. I.: Management of reactive arthritis in a juvenile gorilla (Gorilla gorilla gorilla) with long-term sulfasalazine therapy, J. Zoo Wildlife Med., 31, 539-551, 2000.

Nunn, C., Rothschild, B. M., and Gittleman, J.: Why are some species more commonly afflicted by arthritis than others? A comparative study of spondyloarthropathy in primates and carnivores, J. Evol. Biol., 20, 460-470, 2007.

Ortner, D. J. and Putschar, W. G.: Identificationof Pathological Conditions in Human Skeletal Remains. Smithsonian Contributions to Anthropology \#28, Smithsonian Institution Press, Washington, D.C., 1981.
Powell, M. L. and Collins, D. C.: The Myth of Syphilis: The Natural History of Treponematosis in North America, University of Florida Press, Gainesville, Florida, 2005.

Rahn, H. and Yokoyama, T.: Physiology of Breath-hold Diving and the Ama of Japan, Publication 1341, National Academy of Science, Washington, D.C., 1965.

Resnick, D.: Diagnosis of Bone and Joint Disorders, Saunders, Philadelphia, 2002.

Roberts, C. A.: Paleopathology and its relevance to understanding health and disease today: The impact of the environment on health, past and present, Anthropol. Rev., 79, 1-16, 2016.

Roberts, C. A., Alves Cardoso, F., Bernofsky, K., Henderson, C., Jakob, T., Plomp, K., et al.: Palaeopathology: studying the origin, evolution and frequency of disease in human remains from archaeological sites, UNESCO Encyclopedia of Life Support Systems, available at: http://www.eolss.net/sample-chapters/c04/ e6-59-51.pdf (last access: 10 August 2016), 2012.

Rothschild, B.: Preconceived notions and hypothesis testing: Holes in the Blue Hole. Chungara, Revista de Antropologia Chilena, 32, 141-146, 2000.

Rothschild, B. M.: Rheumatology: A Primary Care Approach, Yorke Medical Press, New York, 1982.

Rothschild, B. M.: Radiologic assessment of osteoarthritis in dinosaurs, Ann. Carnegie Mus., 59, 295-301, 1990.

Rothschild, B. M.: Antiquity of rheumatoid arthritis, Semin. Arthritis Rheum., 23, 355-356, 1994a.

Rothschild, B. M.: Rheumatoid arthritis in a Medieval skeleton: An illogical diagnosis for a case of spondyloarthropathy, Int. J. Osteoarchaeol., 5, 218-219, 1994b.

Rothschild, B. M.: Field guide to joint disease in archeology, Am. J. Phys. Anthropol., 101, 299-301, 1996.

Rothschild, B. M.: Dinosauran paleopathology, in: The Complete Dinosaur, edited by: Farlow, J. O. and Brett-Surman, M. K., Indiana University Press, Indianapolis, Indiana, 427-448, 1997.

Rothschild, B. M.: Rheumatoid arthritis at a time of passage, J. Rheumatol., 28, 245-250, 2001.

Rothschild, B. M.: What qualifies as rheumatoid arthritis?, World J. Rheumatol., 3, 3-5, 2013.

Rothschild, B. M. and Martin, L.: Avascular necrosis: Occurrence in diving cretaceous mosasaurs, Science, 346, 75-7, 1987.

Rothschild, B. M. and Martin, L.: Disease in the Fossil Record, CRC Press, Boca Raton, 1992.

Rothschild, B. M. and Martin, L. D.: Mosasaur ascending: The phylogeny of bends, Neth. J. Geosci., 84, 341-4, 2005.

Rothschild, B. M. and Martin, L.: Skeletal Impact of Disease, New Mexico Museum of Natural History Press, Albuquerque, New Mexico, 2006.

Rothschild, B. M. and Rothschild, C.: Nineteenth century spondyloarthropathy independent of socioeconomic status: Lack of skeletal collection bias, J. Rheumatol., 20, 314-319, 1993.

Rothschild, B. M. and Rothschild, C.: No laughing matter: Spondyloarthropathy in Hyaenidae, J. Zoo Wildlife Med., 25, 259-263, 1994.

Rothschild, B. M. and Rothschild, C.: Treponemal disease revisited: Skeletal discriminators for Yaws, Bejel, and venereal syphilis, Clin. Infect. Dis., 20, 1402-1408, 1995.

Rothschild, B. M. and Rothschild, C.: Analysis of treponemal disease in North Africa: The case for Bejel in the Sudan, but absence in West North Africa, Hum. Evol., 11, 11-15, 1996a. 
Rothschild, B. M. and Rothschild, C.: Epidemic of spondyloarthropathy in baboons, J. Med. Primatol., 25, 69-70, 1996b.

Rothschild, B. M. and Rothschild, C.: Pseudoscience and treponemal disease in the Western Pacific, Curr. Anthropol., 40, 69-71, 1998a.

Rothschild, B. M. and Rothschild, C.: Recognition of hypertrophic osteoarthropathy in skeletal remains, J. Rheumatol., 25, 22212227, 1998b.

Rothschild, B. M. and Rothschild, C.: Spondyloarthropathy as a trans-mammalian phenomenon, reproducible in its manifestations across species lines, J. Paleopathol., 11, 103-104, 2000.

Rothschild, B. M. and Rühli, F. J.: Comparison of arthritis characteristics in lowland Gorilla gorilla and mountain Gorilla beringei, Am. J. Primatol., 66, 205-218, 2005 a.

Rothschild, B. M. and Rühli, F. J.: Etiology of reactive arthritis in Pan paniscus, Pan troglodytes troglodytes and Pan schweinfurthii, Am. J. Primatol., 66, 219-231, 2005b.

Rothschild, B. M. and Woods, R. J.: Spondyloarthropathy in gorillas, Semin. Arthritis Rheum., 18, 267-276, 1989.

Rothschild, B. M. and Woods, R. J.: Symmetrical erosive disease in Archaic Indians: The origin of rheumatoid arthritis in the New World, Semin. Arthritis Rheum., 19, 278-284, 1990.

Rothschild, B. M. and Woods, R. J.: Spondyloarthropathy: Erosive arthritis in representative defleshed bones, Am. J. Phys. Anthropol., 85, 125-134, 1991a.

Rothschild, B. and Woods, R.: Reactive erosive arthritis in chimpanzees, Am. J. Primatol., 25, 49-56, 1991b.

Rothschild, B. M. and Woods, R. J.: Erosive arthritis and spondyloarthropathy in Old World primates, Am. J. Phys. Anthropol., 88, 389-400, 1992a.

Rothschild, B. M. and Woods, R. J.: Spondyloarthropathy as an Old World phenomenon, Semin. Arthritis Rheum., 21, 306-316, 1992b.

Rothschild, B. M. and Woods, R. J.: Arthritis in New World monkeys: Osteoarthritis, calcium pyrophosphate deposition disease and spondyloarthropathy, Int. J. Primatol., 14, 61-78, 1993.

Rothschild, B. M. and Woods, R. J.: Inflammatory arthritis in Pongo, J. Med. Primatol., 25, 414-418, 1996.

Rothschild, B. M., Woods, R. J., and Ortel, W.: Rheumatoid arthritis "In the buff": Erosive arthritis in representative defleshed bones, Am. J. Phys. Anthropol., 82, 441-449, 1990.

Rothschild, B. M., Woods, R. J., and Rothschild, C.: Calcium pyrophosphate deposition disease: Description in defleshed skeletons, Clin. Exp. Rheumat., 10, 557-564, 1992a.

Rothschild, B. M., Woods, R. J., Rothschild, C., and Sebes, J. I.: Geographic distribution of rheumatoid arthritis in ancient North America: Implications for pathogenesis, Semin. Arthritis Rheum., 22, 181-187, 1992b.

Rothschild, B. M., Wang, X.-M., and Cifelli, R.: Spondyloarthropathy in Ursidae: A sexually transmitted disease?, Natl. Geogr. Res. Explor., 9, 382-384, 1993.

Rothschild, B. M., Wang, X.-M., and Shoshani, J.: Spondyloarthropathy in proboscideans, J. Zoo Wildlife Med., 25, 360366, 1994.
Rothschild, B. M., Hershkovitz, I., and Rothschild, C.: Origin of Yaws in Pleistocene East Africa: Homo erectus KNM-ER 1808, Nature, 378, 343-344, 1995.

Rothschild, B. M., Woods, R. J., and Rothschild, C.: Paradox of erosive arthritis in New World monkeys: Collagen-induced versus naturally occurring spondyloarthropathy, Clin. Exp. Rheumatol., 10, 92-93, 1997.

Rothschild, B. M., Rothschild, C., and Woods, R. J.: Inflammatory arthritis in large cats: An expanded spectrum of spondyloarthropathy, J. Zoo Wildlife Med., 29, 279-284, 1998a.

Rothschild, B. M., Sebes, J. I., and Rothschild, C.: Antiquity of Arthritis: Spondyloarthropathy Identified in the Paleocene of North America, Clin. Exp. Rheumatol., 16, 573-575, 1998 b.

Rothschild, B. M., Prothero, D. R., and Rothschild, C.: Origins of spondyloarthropathy in Perissodactyla, Clin. Exp. Rheumatol., 19, 628-632, 2001a.

Rothschild, B. M., Rothschild, C., and Woods, R. J.: Inflammatory arthritis in canids: spondyloarthropathy, J. Zoo Wildlife Med., 32, 58-64, 2001b.

Rothschild, B. M., Coppa, A., and Petrone, P. P.: Like a virgin: Absence of rheumatoid arthritis and treponematosis, good sanitation and only rare gout in Italy prior to the $15^{\text {th }}$ century, Reumatismo, 56, 61-66, 2004.

Rothschild, B. M., Schultze, H.-P., and Peligrini, R.: Herpetological Osteopathology: Annotated Bibliography of Amphibians and Reptiles, Springer-Verlag, Heidelberg, Germany, 2013.

Rothschild, B. M., DePalma, R. A., Burnham, D. A., and Martin, L. D.: Anatomy of a dinosaur - clarification of vertebrae in vertebrate anatomy, Anat. Histol. Embryol., in press, 2016.

Rothschild, C., Rothschild, B., and Hershkovitz, I.: Clues to recognition of kidney disease in archeologic record: Characteristics and occurrence of leontiasis ossea, Rheumatismo, 54, 133-143, 2002.

Savage-Smith, E.: The Practice of Surgery in Islamic Lands: Myth and Reality, Soc. Hist. Med., 13, 307-321, 2000.

Spodick, D. H.: On experts and expertise. The effect of variability in observer performance, Am. J. Cardiol., 36, 592-596, 1975.

Stein, W. W.: The Top 256 Rules of Paleontology, Dragon's Claw Press, Belle Fourche, South Dakota, 2009.

Steinbock, R. T.: Paleopathological diagnosis and interpretation: bone diseases in ancient human populations, Thomas, Springfield, Illinois, 1976.

Stewart, T. D. and Spoehr, A.: Evidence on the paleopathology of yaws, Bull. Hist. Med., 26, 538-553, 1952.

Walker, A., Zimmerman, M. R., and Leakey, R. E.: A possible cause of hypervitaminosis A in Homo erectus, Nature, 296, 248-250, 1982.

West, B. T., Sakshaug, J. W., and Aurelien, G. A.: How big of a problem is analytic error in secondary analyses of survey data?, PLoS ONE, doi:10.1371/journal.pone.0158120, in press, 2016.

Wolff, E. D.: The discovery of two novel archosaur diseases with implications for future paleopathological exploration, Hist. Biol., 20, 185-189, 2008. 